\title{
TESLA Vertical Test Dewar Cryogenic and Mechanical Design
}

Thomas H. Nicol, Donald E. Arnold and Mark S. Champion

Fermi National Accelerator Laboratory

P.O. Box 500, Batavia, Illinois 60510

May 1993

Presented at the 1993 Particle Accelerator Conference, Washington, D.C., May 17-20, 1993 


\section{Disclaimer}

This report was prepared as an account of work sponsored by an agency of the United States Government. Neither the United States Government nor any agency thereof, nor any of their employees, makes any warranty, express or implied, or assumes any legal liability or responsibility for the accuracy, completeness, or usefulness of any information, apparatus, product, or process disclosed, or represents that its use would not infringe privately owned rights. Reference herein to any specific commercial product, process, or service by trade name, trademark, manufacturer, or otherwise, does not necessarily constitute or imply its endorsement, recommendation, or favoring by the United States Government or any agency thereof. The views and opinions of authors expressed herein do not necessarily state or reflect those of the United States Government or any agency thereof. 


\title{
TESLA Vertical Test Dewar Cryogenic and Mechanical Design
}

\author{
Thomas H. Nicol, Donald E. Arnold, and Mark S. Champion \\ Fermi National Accelerator Laboratory* \\ P.O. Box 500, Batavia, IL 60510 USA
}

\begin{abstract}
Collaborators on the design of a Tevatron Superconducting Linear Accelerator (TESLA) are working toward construction of a test cell consisting of four full length cryostats, 12 meters long, each containing eight, 9-cell superconducting $R F$ cavities. In order to ensure that each cavity meets its performance requirements, 'as received' structures will be tested in a vertical dewar prior to installation in the cryostat vessels. In addition, the dewar system will accommodate cavities installed in their helium containment vessels for testing if performance problems occur during later stages of fabrication. The vertical dewar system permits testing of the RF performance and high power processing of the cavity structures at their operating temperature of $1.8 \mathrm{~K}$. The design of the cryogenic system, vacuum system, RF input, test instrumentation, and tuning system will be described in detail.
\end{abstract}

\section{INTRODUCTION}

The design center for the TESLA collaboration is the Deutsches Elektronen Synchrotron (DESY) in Hamburg, Germany. The initial focus of this collaboration is the construction of a test facility consisting of four 12-meter long cryostats containing eight 9-cell RF cavities. Each cavity is approximately one meter long and is contained in its own helium containment vessel. Prior to assembly, each cavity must be tested to ensure that its performance meets the design criteria. ${ }^{1}$ In addition, one would like to be able to test cavities after they have been welded into their helium shells to verify that performance has not been degraded during assembly processing.

The initial testing on all cavities received from manufacturing is done in a vertical dewar. This dewar provides the capability of testing 'as received' cavities at $1.8 \mathrm{~K}$ under full RF power. It also allows high power processing of cavities to enhance performance which may be degraded due to surface contamination. As such the dewar consists of a complete cryogenic system as well as an RF insert for powering the cavity. The cryogenic system consists of an inner helium vessel, an $\mathrm{LN}_{2}$ shield, and an outer insulating vacuum vessel. The RF insert consists of the cavity itself, the input

* Operated by Universities Research Association under contract with the U.S. Department of Energy. waveguide, a waveguide to coaxial transition, an $R F$ tuning system, and supporting instrumentation.

\section{CRYOGENIC SYSTEM}

During the initial design phase of the TESLA cryogenic system a distribution box was envisioned which attached to a conventional helium liquefaction plant at DESY. The purpose of the distribution box was two-fold. First it was to contain heat exchangers to subcool liquid prior to distribution to the remainder of the system, including the vertical dewar. Second it was to provide valving for independent control of all downstream devices. To simplify the design of this distribution system, the heat exchangers and J-T valves for subcooling $4.5 \mathrm{~K}$ helium to $1.8 \mathrm{~K}$ were moved to the individual downstream devices. As such the design of the vertical test dewar involves more than a helium vessel, $\mathrm{LN}_{2}$ shield, and insulating vacuum vessel. Figure 1 illustrates the cryogenic system in the vertical dewar. Helium at $4.5 \mathrm{~K}$ is supplied through a warmup and cooldown valve to the bottom of the inner vessel for initial filling. After the vessel is full, this valve is closed and flow passes through the tube side of a heat exchanger which provides counterflow exchange with gas being pumped from the liquid volume. The subcooled inlet flow, initially at $4.5 \mathrm{~K}$, enters the inner helium vessel and is controlled by a J-T valve. The gas flow on the shell side of the heat exchanger is pumped by cold vacuum compressors and is controlled by a 60 $\mathrm{mm}$ isolation valve. The design flow in all the piping circuits is $5 \mathrm{grams} / \mathrm{sec}$ helium. The heat exchanger and all of the valves are located in the annular space between the inner helium vessel and the $\mathrm{LN}_{2}$ shield.

\section{VACUUM SYSTEM}

RF power to the cavity under test is supplied through a full-height WR650 waveguide. At the cavity connection a transition is made to a coaxial connector into the cavity itself. To minimize the potential for damage to the cavity in the event of a failure in the waveguide system, a ceramic window is installed at the waveguide to coaxial transition. This necessitates the use of two separate vacuum systems; one for the waveguide capable of achieving $10^{-7}$ torr or better and one for the cavity system capable of $10^{-8}$ torr or better. At this writing, it was unclear what type of pumping 
systems would be employed in these applications. Similar dewar systems in use rely primarily on ion pumps. There is some risk with ion pumps, however, of titanium contamination in the cavity. In fact, such contamination has been observed and is a concern for these systems. The waveguide and cavity vacuum systems for this vertical dewar will likely be pumped by means of high speed turbo-pumps. They provide the pumping capacity required and eliminate the potential contamination problems. Once operating vacuums are achieved the pumping systems will be taken off-line, precluding the potential concern about vibration induced cavity resonances.

\section{RF INSERT}

The previous sections outlined the requirements of the cryogenic and vacuum systems for the vertical dewar. These are only services for operation of the actual device under test, i.e. the RF cavity. The actual cavity is only a small part of the components suspended in the dewar, the sum total of which is referred to as the $\mathrm{RF}$ insert. This insert is suspended from the inner vessel closure plate and consists of the cavity, $R F$ waveguide, waveguide to coaxial transition ('doorknob'), and RF tuning system. Figure 2 illustrates a cross section of the dewar with the RF insert installed.

The waveguide is a full-height WR650 assembly fabricated from stainless steel to minimize heat load into the $1.8 \mathrm{~K}$ bath and copper plated for good RF conductance. A room temperature window and a cold cylindrical ceramic window isolate the waveguide vacuum from atmosphere at the warm end and from the cavity vacuum at the cold end.

The doorknob transition converts the rectangular waveguide to a coaxial coupler. The outer conductor of

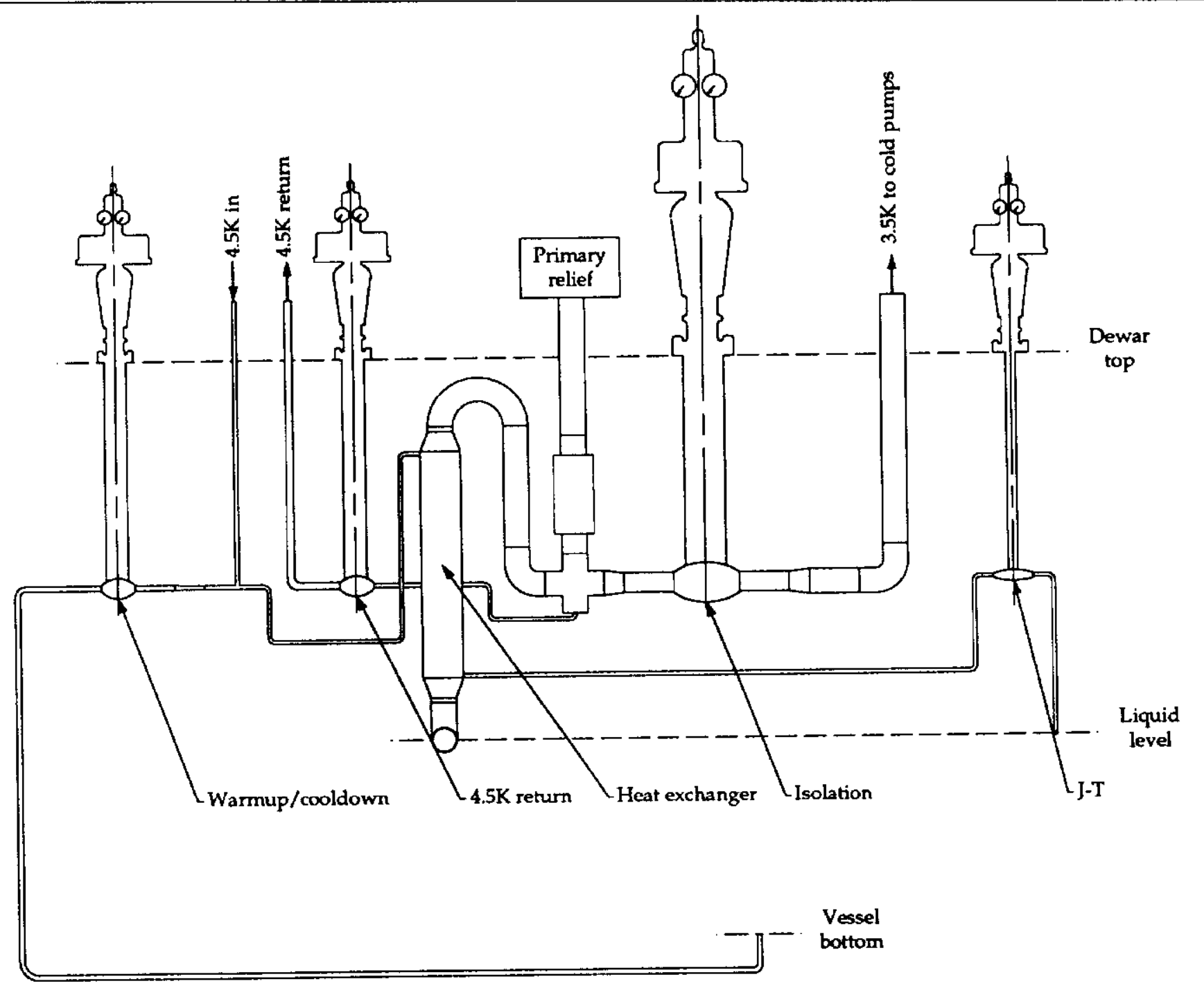

Figure 1. Cryogenic piping layout 
the coax is a copper plated stainless steel bellows which allows the cavity to be raised and lowered with respect to the center coaxial conductor. This provides the tuning capability needed to match the RF performance of the coupler to each individual cavity. Movement of the cavity is provided by means of a linear drive system mounted to the top plate of the RF insert. The drive

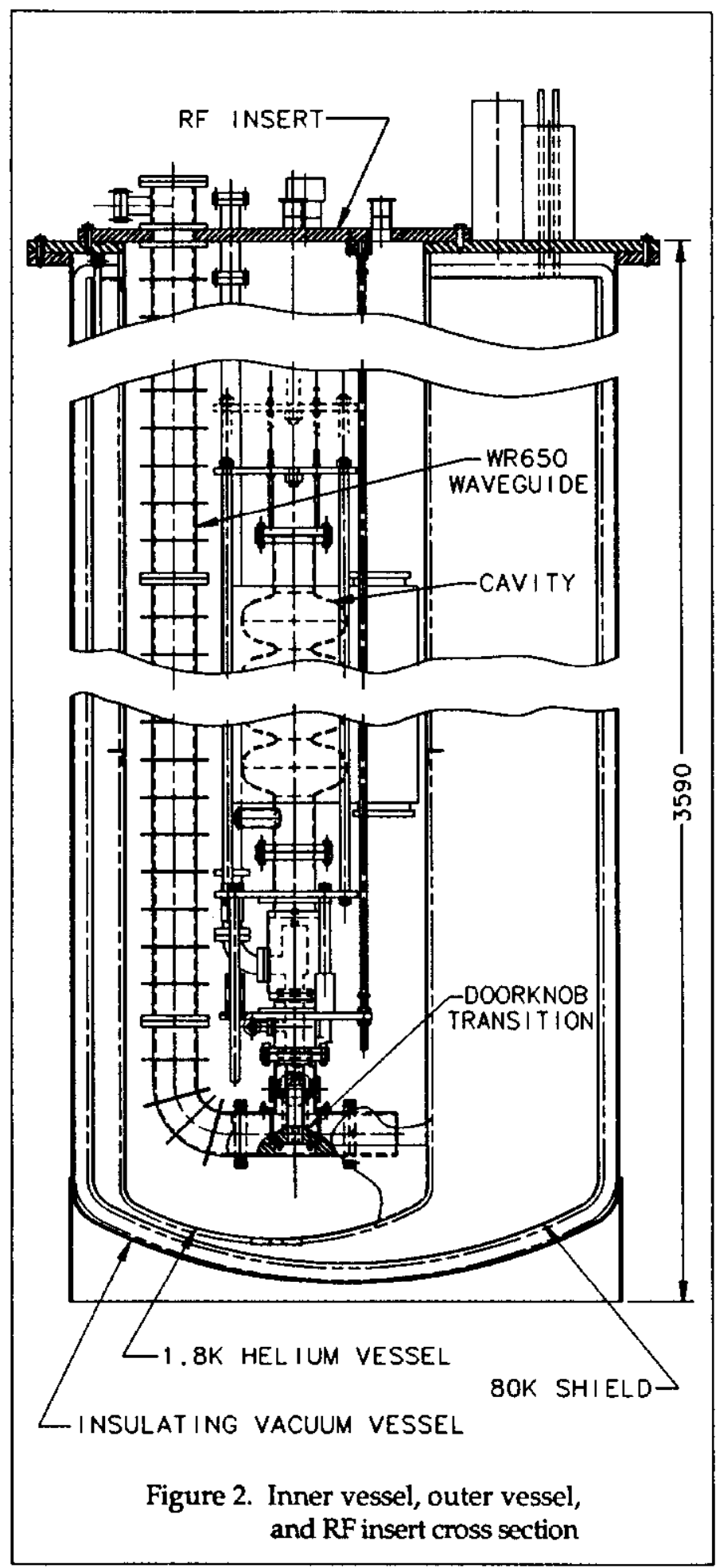

system provides $100 \mathrm{~mm}$ total vertical adjustment of the cavity position relative to the center conductor of the coaxial assembly.

\section{INSTRUMENTATION}

Instrumentation will be provided to measure the thermal and RF performance of the dewar and RF systems. Although complete requirements have not been defined as of this writing, the following illustrates a partial list of the instrumentation requirements.

- Helium level probe

- Thermometers for cavity temperature mapping and quench detection

- RF measuring probes for the cavity and high order mode couplers

- Electron detectors for the high order mode couplers

- Accelerometers

- Pressure transducers for the LHe volume

- Light monitors for the cold ceramic window

- Bake-out heaters

- X-ray monitor and spectrometer

- Cavity, waveguide, and insulating vacuum gauges

\section{SUMMARY}

Fermilab is responsible for fabrication of the complete vertical dewar system, i.e. the inner LHe vessel, $\mathrm{LN}_{2}$ shield, outer vacuum vessel, and $R F$ insert. Due to both ASME and German pressure vessel code requirements on the inner vessel, it is being fabricated by a commercial manufacturer. Fermilab will install and test all the piping, valves, access ports, partial instrumentation, and other mechanical equipment. The present schedule requires that the first vessel be shipped to DESY for installation in the TESLA test facility late in the summer of 1993. Current plans provide for fabrication of a second, identical dewar in fiscal year 1994.

\section{REFERENCES}

[1] A Proposal to Construct and Test Prototype Superconducting RF Structures for Linear Colliders, (DESY, April 1992). 